\title{
INTRA-SPECIFIC DIVERGENCE IN THE WESTERN AUSTRALIAN FROG RANIDELLA INSIGNIFERA
}

\section{THE EVIDENCE FROM GENE FREQUENCIES AND GENETIC DISTANCE}

\author{
JENEFER M. BLACKWELL* \\ Department of Zoology, University of Western Australia, Nedlands, Western Australia 6009
}

Received 26.viii.77

\begin{abstract}
Summary
Analysis of gene frequencies at ten enzyme loci (six polymorphic) failed to produce any evidence that races exist in the frog Ranidella insignifera associated with the edaphic feature of sand and clay based ponds. Most polymorphic loci exhibited macrogeographic uniformity of allele frequencies but in no case had any one allele become fixed in any one population. Nor were there any alleles unique to sand populations only or to clay populations only. Genetic distance algorithms failed to show any intra-specific divergence intermediate between inter-population and inter-sibling species levels.
\end{abstract}

\section{InTRODUCTION}

ON the basis of aurally distinguishable differences in male mating call Main (1957) divided the leptodactylid frog species, Ranidella insignifera (recently removed from the genus Crinia by Blake, 1973) from south-western Australia into three call-types: Coastal harsh voice (Chv), Coastal clay (Cc), and Plateau harsh voice (Phv). Phv appeared to remain unchanged over its range and absence of intergrading calls with either Chv or Gc indicated a lack of gene flow. Phv was therefore regarded as a valid species, $R$. pseudinsignifera, reproductively isolated from $R$. insignifera. Intergradation of calls, in some localities abruptly and in others in a more gradual manner, demonstrated the presence of gene flow between Chv and Cc which were then regarded as two races of one polytypic species, $R$. insignifera. In examining similarities of male mating call and genetic closeness demonstrated by laboratory hybridisation experiments of Eastern and Western Australian species of the genus Ranidella, Main, Lee and Littlejohn (1958) further proposed that $R$. pseudinsignifera and $R$. insignifera arose through successive migrations from an ancestral Eastern Australian species during the pluvials of the Pleistocene period.

Detailed call analysis (Littlejohn, 1959) demonstrated measureable differences between the male mating calls of the two species, $R$. insignifera and $R$. pseudinsignifera, but not between the proposed $\mathrm{Chv}$ and $\mathrm{Cc}$ races. Other studies on the inviability of inter-race crosses, temporal isolation, developmental differences at the tadpole stage, and morph ratios of body pattern (Hodgson, 1964) supported the existence of the two races. Subsequently a similar study of five local populations at a sand/clay interface (Jones, 1966) demonstrated a different and unique set of genetic charac-

* Present address: Ross Institute of Tropical Hygiene, London School of Hygiene and Tropical Medicine, Keppel St (Gower St), London WG1E 7HT.

$40 / 3$ - A 
teristics for each population. Main (1968) then reported differences in mean breeding temperature for animals in clay and sand-based ponds and continued to prefer the racial distinction.

Recently, genetic distance measures have been proposed (e.g. Nei, 1971 and 1972; Rogers, 1972) to summarise gene frequency data over many loci and thereby assess overall genetic similarity of differentiation between pairs of populations, pairs of races or subspecies, pairs of sibling species, and pairs of non-sibling species. Although it is not possible to generalise on the absolute degree of differentiation accompanying different levels of evolution in different groups of organisms (e.g. see Selander and Johnson, 1973, tables 3 and 4), the results of Tracey (1973) on the Drosophila willistoni group indicate that within any one group different levels of divergence may show increasing and characteristic genetic distances. Using the known sibling species comparison with $R$. pseudinsignifera as a baseline the status of the proposed intraspecific divergence in $R$. insignifera has been examined using the modern gene frequency and genetic distance methods. At the same time studies have been carried out (Blackwell, 1974 and unpublished) to determine the status of this intra-specific divergence at the level of pre- and post-mating isolation.

\section{MEthods}

Sexually mature male frogs were collected during the breeding season from 10 populations of $R$. insignifera including populations across three sand/clay boundaries, and from two populations of $R$. pseudinsignifera (see map fig. 1). Liver homogenates from these animals were prepared and electrophoresced according to the methods described in Blackwell and Bull (1978) staining for non-specific esterases (Est), lactic dehydrogenase (LDH), glutamic dehydrogenase (GDH), and superoxide dismutase (SOD).

To determine the genetics of these enzyme systems in vitro crosses were made (after the method of Rugh, 1948) between natural mating pairs of both $R$. insignifera and $R$. pseudinsignifera. Tadpole progeny from each cross were divided into several batches of 30 animals and transferred to large outdoor bowls ( 3.5 litre) where they could develop to metamorphosis by browsing on natural algal growth. The newly metamorphosed frogs of approximately $6 \mathrm{~mm}$ length were then reared in the laboratory on Drosophila spp. larvae and adults to about 10 to $13 \mathrm{~mm}$ in length before being sacrificed for liver samples (adult length ranges from 15 to $23 \mathrm{~mm}$ ).

The distribution of loci and alleles was predicted following examination of the electrophoretic banding patterns of parents and progeny. Standard chi-squared tests were then used to test observed against expected genotypic proportions in the progeny.

Migration distances for each allele at each locus were expressed as a proportion of a selected Ranidella band designated the value $1 \cdot 00$. This was usually the fastest migrating allele at the fastest migrating locus being used in gene frequency estimates. The genotype of each animal in the 12 population samples was recorded and gene frequencies for each allele at each locus were calculated.

Gene frequencies were used to calculate genetic distance between pairwise comparisons of all populations according to the algorithms of Rogers (1972) and Nei (1971 and 1972). Populations of $R$. insignifera were then 
grouped according to pond substrate type (sand $v$. clay) and mean distances between populations within each group were computed and compared with mean distances between populations of the two groups and between $R$. insignifera and $R$. pseudinsignifera. These mean distances were calculated from two matrices derived (1) from monomorphic and polymorphic loci for which the two species shared alleles and (2) after the addition of loci which were diagnostic for the two species.

Mean distances between $R$. insignifera populations in the Bunbury area (fig. 1, populations 1, 2, and 3) and in the Perth area (fig. 1, populations 4 to 10) were also computed and compared with mean distances between populations of the two areas. Similar comparisons were made using two local population groups within the Perth area, Perth 1 (fig. 1, populations 4 and 5) and Perth 2 (fig. 1, populations 7, 8, and 9). These mean distances were all calculated from matrices derived from all $R$. insignifera loci.

\section{Results}

Severe mortality in the period from hatching to metamorphosis (taking in excess of 3 months) and again when attempting to get newly metamorphosed frogs to feed in the laboratory greatly reduced the number of successful crosses available for studying the genetics of enzyme systems. When the juveniles had reached 10 to $13 \mathrm{~mm}$ in length (taking a further 3 months from the time of metamorphosis) a third bout of mortality began. A preliminary test of the juveniles at this stage revealed that adult enzymes were present and that the livers were large enough (approximately $9 \mathrm{mg}$ compared to adult liver weights of 13 to $15 \mathrm{mg}$ ) to homogenise satisfactorily. Finally, the genotypes of parentals and progeny of four crosses, two $R$. insignifera (cross A from Thornlie Sand, cross B from Middle Swan Clay) and two $R$. pseudinsignifera (both from a population at Jacoby St near Glen Forrest, see Blackwell and Bull, 1978) were obtained (see table 1). Only one locus in one cross (LDH-2, cross B) showed a significant difference between observed and expected genotypic proportions according to the following genetic systems: (i) Non-specific esterases (Est). At least five loci control Est activity in the two species all of which are multi-allelic with two or three banded heterozygotes. Est-1 was present only in $R$. pseudinsignifera but not in all animals. Some switching mechanism or silent alleles must be operating at this locus. Bands were never observed in the homologous position in $R$. insignifera. Est-3 was present only in $R$. pseudinsignifera and Est-4 was present only in $R$. insignifera. Hybrids examined by Blackwell and Bull (1978) could be heterozygous for both loci; (ii) Lactic dehydrogenase $(\mathrm{LDH})$. This enzyme is a five banded tetramer controlled by two loci, LDH-1 which is monomorphic and LDH-2 which is di-allelic, in the two species; (iii) Glutamic dehydrogenase (GDH). One monomorphic locus, GDH-1, was verified by the breeding data. Other faint bands which could be coded for by more than one locus were present closer to the origin; (iv) Superoxide dismutase (SOD). Five bands moving furthest from the origin were identified as a tetramer controlled by two loci, SOD-1 and SOD2 , monomorphic for the same alleles in both species. Other bands present closer to the origin did not appear consistently in all gels and were omitted from the analysis.

Divergence between the two species $R$. insignifera and $R$. pseudinsignifera 


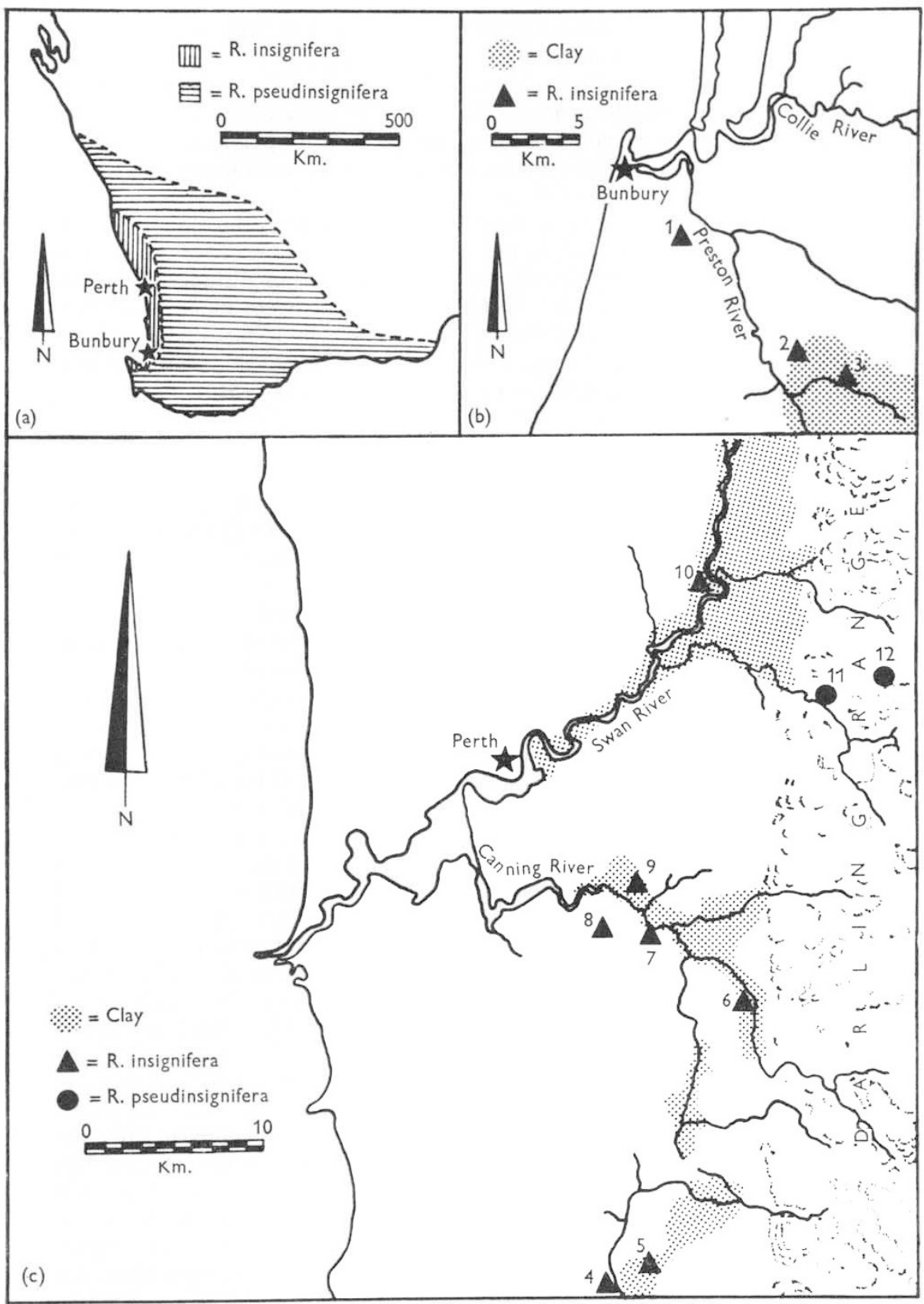

Fig. 1.-Maps of portions of Western Australia showing: (A) the distribution of $R$. insignifera and $R$. pseudinsignifera in the south-west corner; (B) details of the Bunbury region giving locations for Bunbury Sand (1), Garvey Sand/Clay (2), and Dillon Clay (3) $R$. insignifera populations; and $(\mathrm{C})$ details of the Perth region giving locations for Orton Sand (4), Kargotich Clay (5), Seaforth Clay (6), Thornlie Sand (7), Cannington Sand (8), Cannington Clay (9), and Middle Swan Clay (10) R. insignifera populations and Boya Quarry (11) and Glen Forrest (12) R. pseudinsignifera populations. 
TABLe 1

Parental genotypes and observed numbers of their progeny in intra-specific crosses of $\mathrm{R}$. insignifera ( $A$ and $B)$ and R. pseudinsignifera ( $C$ and $D)$ for Est, $L D H, G D H$, and SOD enzyme systems. Alleles are designated by their relative migration distances (see text)

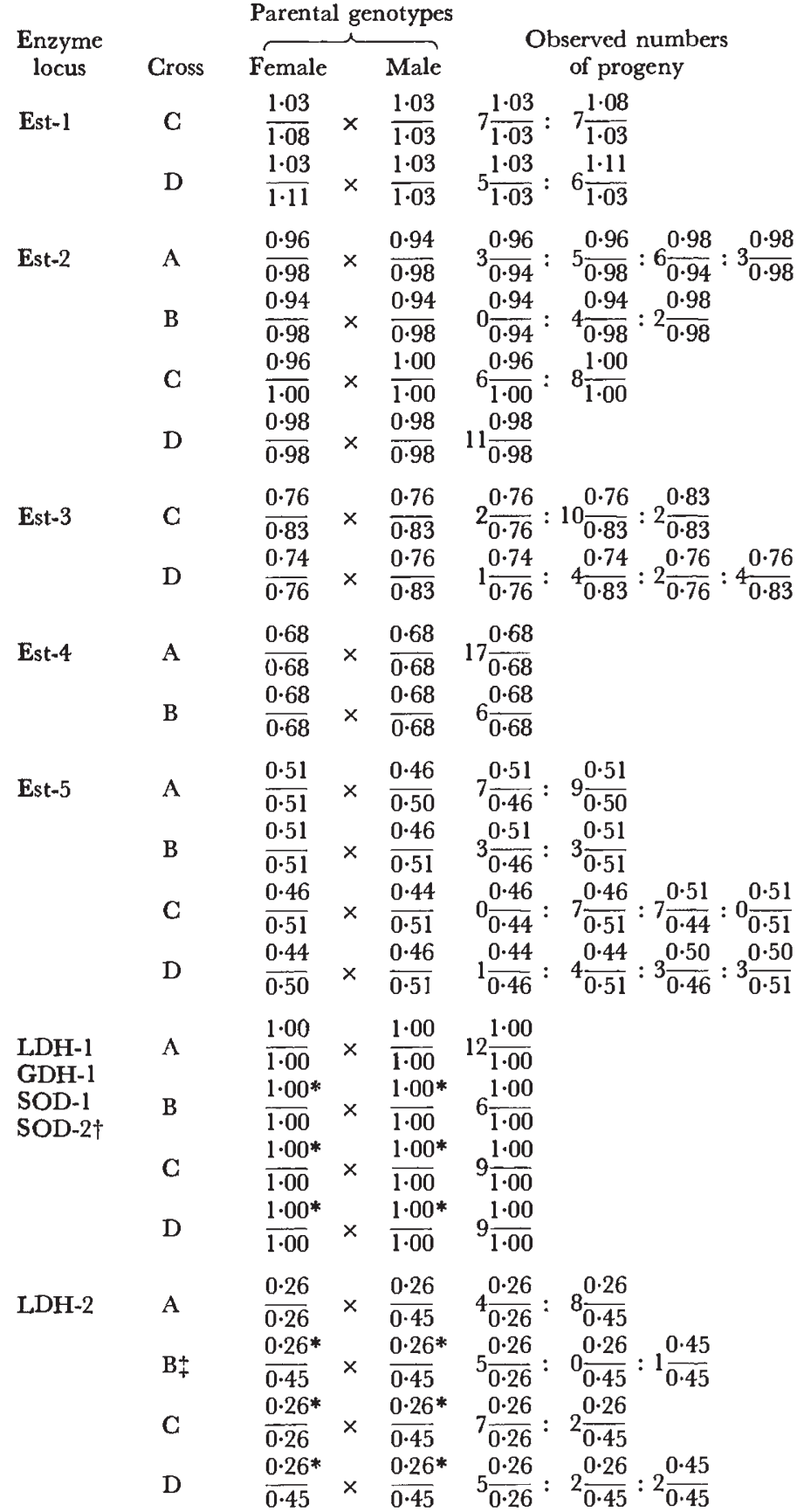

* Parental genotypes not tested for LDH; † Migration distance for SOD-2 is $0 \cdot 64$; $\ddagger$ Observed numbers of progeny differed from expected $(0.02<p<0.05)$. 
at three loci (Est-1, Est-3, and Est-4) was immediately apparent when gene frequencies for the 10 enzyme loci were calculated for the 12 populations sampled (see table 2). Similar evidence for sand/clay race divergence is not apparent when the distribution of alleles over sand and clay populations of $R$. insignifera is examined. Two alleles at LDH-2, six at Est-2, three at Est-4, and five at Est-5 are present in $R$. insignifera and all occur in varying frequencies in both sand and clay populations. For Est-2 and Est-4 the same allele has the highest frequency in all populations and for Est-5 two alleles are more common throughout most populations than the remaining three.

The results of grouping populations to compute mean genetic distance between sand and clay populations within $R$. insignifera and between $R$. insignifera and $R$. pseudinsignifera are shown in table 3 . The first comparison was made using monomorphic loci and polymorphic loci for which both species shared most alleles. Even so, for both Rogers' and Nei's genetic distance algorithms mean distance between the two species is higher than any within $R$. insignifera comparisons. As expected the addition of the diagnostic loci Est-1, Est-3 and Est-4 produced higher mean distances between the species but did not significantly alter the magnitude of withinspecies mean distances.

If sand and clay races exist the sand and clay comparison might be expected to yield mean distances intermediate between the other intraspecific comparisons and the inter-specific comparisons. On the contrary, as the macrogeographic uniformity of allele frequencies would suggest, the mean distances computed between all $R$. insignifera, between all clay, between all sand, and sand against clay populations were of the same order of magnitude and variability around the mean for both enzyme groups and for both distance algorithms. The alternative within species comparison (see table 4) produced similar mean distances between geographically close and distant populations all of which were of the same order of magnitude as the clay and sand comparisons. There thus appears to be no intraspecific differentiation within $R$. insignifera beyond the level of local population variation, at least for the loci examined in this study.

\section{Discussion}

This study has shown that the divergence of male mating call in the sibling species $R$. insignifera and $R$. pseudinsignifera first noted by Main (1957) has been accompanied by the evolution of species-specific differences at enzyme loci. Blackwell and Bull (1978) have also shown that the narrow hybrid zone between the two species can be accurately described using allele frequencies at these loci, with the degree of hybridisation in each population across the boundary conforming with amounts measured by analysis of the polygenic characters of male mating call and morphometrics of skeletal elements. Detailed study of mitotic cell karyotypes and of inter-species crosses by Bull (1973) did not, however, reveal differences between the two species.

Similar situations have been found by other workers for divergence at subspecific levels. Selander, Hunt and Yang (1969) showed that alternate alleles are fixed or nearly fixed at enzyme loci in the two subspecies Mus musculus musculus and $M . m$. domesticus which can be otherwise identified by 


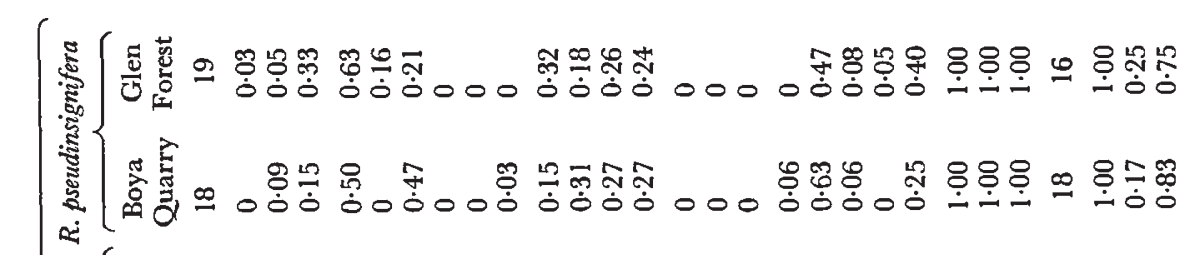

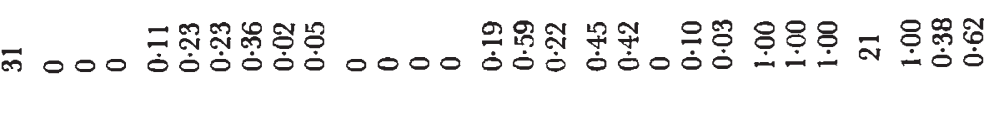

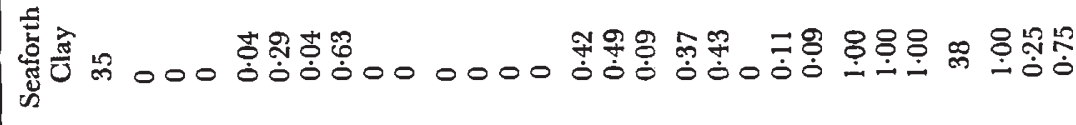
.

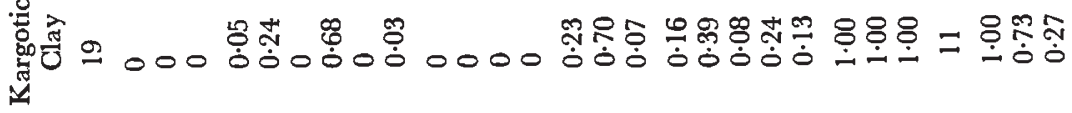

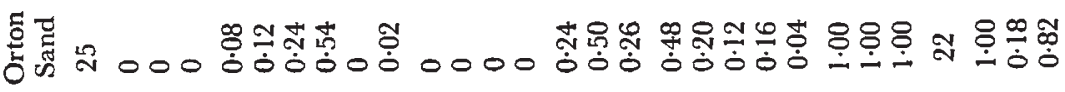

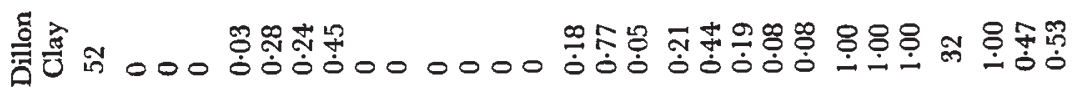
总U

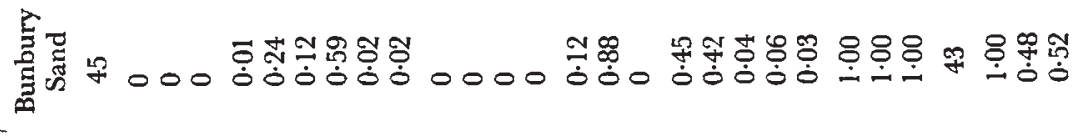

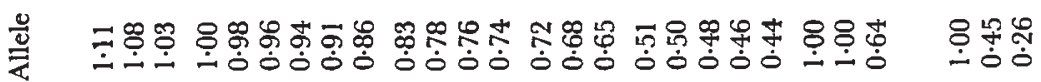

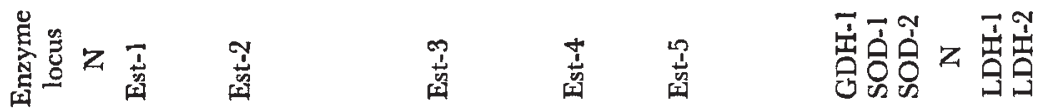


TABLE 3

Mean genetic distances between groups of sand and clay populations of $\mathrm{R}$. insignifera and between populations of R. insignifera and R. pseudinsignifera computed from matrices of Rogers' and Nei's coefficients. $\mathcal{N}=$ number of population comparisons within each group

\begin{tabular}{lllcc} 
Enzyme loci & \multicolumn{1}{c}{ Groups of populations } & N & Rogers' D \pm S.E. & Nei's D \pm S.E. \\
Group A & Between all $R$. insignifera & 45 & $0 \cdot 078 \pm 0 \cdot 004$ & $0 \cdot 025 \pm 0 \cdot 003$ \\
Est-2, Est-5, & Between all clay $R$. insignifera & 10 & $0 \cdot 085 \pm 0 \cdot 008$ & $0 \cdot 029 \pm 0 \cdot 005$ \\
LDH-1, LDH-2, & Between all sand $R$. insignifera & 10 & $0 \cdot 065 \pm 0 \cdot 004$ & $0 \cdot 016 \pm 0 \cdot 002$ \\
GDH-1, SOD-1, & Sand against clay $R$. insignifera & 25 & $0 \cdot 080 \pm 0 \cdot 007$ & $0 \cdot 028 \pm 0 \cdot 004$ \\
SOD-2. & R. insignifera against $R$. pseudinsignifera & 20 & $0 \cdot 161 \pm 0 \cdot 006$ & $0 \cdot 103 \pm 0 \cdot 007$ \\
Group B & Between all $R$. insignifera & 45 & $0 \cdot 072 \pm 0 \cdot 003$ & $0 \cdot 029 \pm 0 \cdot 003$ \\
Group A+ & Between all clay $R$. insignifera & 10 & $0 \cdot 075 \pm 0 \cdot 007$ & $0 \cdot 032 \pm 0 \cdot 005$ \\
Est-1, Est-3, & Between all sand $R$. insignifera & 10 & $0 \cdot 064 \pm 0 \cdot 004$ & $0 \cdot 021 \pm 0 \cdot 003$ \\
Est-4. & Sand against clay $R$. insignifera & 25 & $0 \cdot 073 \pm 0 \cdot 004$ & $0 \cdot 032 \pm 0 \cdot 004$ \\
& $R$. insignifera against $R$. pseudinsignifera & 20 & $0 \cdot 218 \pm 0 \cdot 005$ & $0 \cdot 180 \pm 0 \cdot 008$
\end{tabular}

TABLE 4

Mean genetic distances between groups of populations of $\mathbf{R}$. insignifera from different geographical regions computed from matrices of Rogers' and $\mathcal{N} e i$ 's coefficients using all $\mathrm{R}$. insignifera loci. $\mathcal{N}=$ number of population comparisons within each group

\begin{tabular}{lrcc}
\multicolumn{1}{c}{ Groups of populations } & N & Rogers' D \pm S.E. & Nei's D \pm S.E. \\
Between Bunbury & 3 & $0 \cdot 050 \pm 0 \cdot 003$ & $0.012 \pm 0.001$ \\
Between all Perth & 21 & $0.073 \pm 0.006$ & $0.033 \pm 0.005$ \\
Bunbury against all Perth & 21 & $0 \cdot 074 \pm 0.003$ & $0.028 \pm 0.002$ \\
Between Perth 1 & 1 & $0 \cdot 124$ & 0.083 \\
Bunbury against Perth 1 & 6 & $0.085 \pm 0.005$ & $0.037 \pm 0.004$ \\
Between Perth 2 & 3 & $0.077 \pm 0.006$ & $0.034 \pm 0.008$ \\
Bunbury against Perth 2 & 9 & $0.067 \pm 0.004$ & $0.023 \pm 0.003$ \\
Perth 1 against Perth 2 & 6 & $0.073 \pm 0.012$ & $0.035 \pm 0.010$
\end{tabular}

morphological and behavioural differences. As in Ranidella, the position of the zone of hybridisation at secondary contact measured by enzyme gene frequencies (Hunt and Selander, 1973) conforms with that defined by Ursin (1952) using morphological characters. In the bluegill Lepomis macrochirus two subspecies identifiable on the basis of morphological and physiological characters have gone to fixation for different alleles at two enzyme loci (Avise and Smith, 1974). At their zone of secondary contact the degree of introgression appears to be equal for alleles at both loci. Two races of Drosophila mojavensis which differ in overall morphology and chromosomal inversions are fixed or nearly fixed for alternate alleles at several enzyme loci (Zouros, 1973). An analysis of gene frequencies at a number of enzyme loci in populations of $R$. insignifera might, therefore, have been expected to yield some similar differences between the proposed sand and clay races even if some mixing occurs at the sand/clay interface. In fact, no alleles for any of the polymorphic loci examined had become fixed or even reached very high frequencies in any population. Other loci were monomorphic for the same alleles throughout the $R$. insignifera range.

In all of the cases described above the enzyme differences were reflected in higher between than within subspecies or race mean genetic distances. In a study of the Drosophila bipectinata species complex Yang, Wheeler and Bock (1972) were able to separate species on genetic distance even in situations where species had not gone to fixation for alternate alleles at any 
loci. For example, $D$. bipectinata and $D$. parabipectinata shared at least one allele at every enzyme locus examined but alleles at several loci unique to each species all contributed to produce higher genetic distances between than within species. A similar result was obtained in this study when gene frequencies for the non-diagnostic enzyme loci were used to compute mean genetic distances within $R$. insignifera and between $R$. insignifer $a$ and $R$. pseudinsignifera. Although the magnitude of genetic distance increased between species when the diagnostic loci were added, the two species could still be separated on the non-diagnostic loci. Within $R$. insignifera, however, there were no alleles unique to sand populations only or to clay populations only. Consequently, the genetic distance algorithms failed to show any intra-specific distances intermediate between inter-population and intersibling species levels.

This evidence may not in itself be sufficient to dismiss the notion that divergence has occurred within $R$. insignifera. Just as divergence between $R$. insignifera and $R$. pseudinsignifera has not resulted in detectable chromosomal differences or post-mating inviability, so situations may be found where enzyme loci have not diverged to match chromosomal, morphological or sexual isolation data (e.g. see Sene and Carson, 1976). Besides, it might simply be argued that sufficient enzyme loci have not yet been examined to pick up the differences. However, the results of Littlejohn (1959) have already cast doubt on Main's (1957) " aurally distinguishable " differences in male mating call and the results of Blackwell (1974 and unpubl.) now show: (1) that temporal and behavioural barriers to gene flow between sand and clay populations (Hodgson, 1964; Main, 1968) are not effective every year; and (2) that when variability in fertility between males and between females of the same populations is taken into account, no interpopulation (and hence no inter-race) inviability of crosses such as led Hodgson (1964) to support Main's theory occurs. The credibility of Main's (1957 and 1968) sand/clay race concept is therefore questioned.

Acknowledgments. - This work was carried out under the supervision of Professors H. E. Paterson and A. R. Main whilst the author was holding a Commonwealth Postgraduate Research Award at the University of Western Australia. Dr Godfrey Hewitt and Professor Bryan Clarke kindly provided constructive criticism of the manuscript. Dr Simon Miles provided invaluable assistance in the field and Dr Michael Bull supplied animals from $R$. pseudinsignifera populations.

\section{REFERENCES}

AVISE, J. C., AND SMITH, M. H. 1974. Biochemical genetics of sunfish. I. Geographic variation and subspecific intergradation in the Bluegill, Lepomis macrochirus. Evolution, 28, 42-57.

BLACKWELl, J. M. 1974. The structure of the deme in the frog Crinia insignifera Moore, 1954. Ph.D. Thesis, Zoology Department, University of Western Australia.

BLACKWELL, J. M., AND BULL, C. M. 1978. A narrow hybrid zone between two Western Australian frogs, Ranidella insignifera and $R$. pseudinsignifera: the extent of introgression. Heredity, 40, 13-25.

BLAKE, A. J. D. 1973. Taxonomy and relationships of myobatrachine frogs (Leptodactylidae) : a numerical approach. Aust. F. Zool., 21, 119-149.

BuLl, c. M. 1973. The interactions of two allopatric frog species at their common boundary. Ph.D. Thesis, Zoology Department, University of Western Australia.

Hodgson, s. M. 1964. Behaviour and evolution of Crinia. B.Sc. Honours Thesis, Zoology Department, University of Western Australia.

HUNT, W. G., AND SELANDER, R. K. 1973. Biochemical genetics of hybridisation in European house mice. Heredity, 31, 11-33. 
JONEs, R. 1966. A study of the characteristics of local populations of Crinia insignifera. B.Sc. Honours Thesis, Zoology Department, University of Western Australia.

LitTLEjohn, M. J. 1959. Call differentiation in a complex of seven species of Crinia (Anura: Leptodactylidae). Evolution, 13, 452-468.

main, A. R. 1957. Studies in Australian amphibia. I. The genus Crinia Tschudi in S-W Australia and some species from S-E Australia. Aust. F. Zool., 5, 30-55.

Marn, A. R. 1968. Ecology, systematics and evolution of Australian frogs. Adv. Ecol. Res., $5,37-86$.

MAIN, A. R., LEE, A. K., AND LITTLEJOHN, M. J. 1958. Evolution in three genera of Australian frogs. Evolution, 12, 224-233.

NEI, M. 1971. Interspecific gene differences and evolutionary time estimated from electrophoretic data on protein identity. Amer. Nat., 105, 385-398.

NEI, M. 1972. Genetic distance between populations. Amer. Nat., 106, 283-292.

ROGERs, J. S. 1972. Measures of genetic similarity and genetic distance. Studies in Genetics VII, Univ. Texas Publ. 7213, 145-153.

RUGH, R. 1948. Experimental Embryology. Burgess Publ. Co., Minneapolis.

SELANDER, R. K., HUNT, W. G., AND YANG, s. Y. 1969. Protein polymorphism and genic heterozygosity in two European subspecies of the house mouse. Evolution, 23, 379-390.

SELANDER, R. K., AND JOHNSON, W. E. 1973. Genetic variation among vertebrate species. Ann. Rev. Ecol. Syst., 4, 75-91.

SENE, F. M., AND CARSON, H. L. 1976. Close allozymic similarity within and between two sympatric species of Hawaiian Drosophila. Genetics, 83, s69-s70.

TRACEY, M. L. 1973. How much genetic differentiation accompanies the process of speciation. Genetics, 74, s279.

URSIN, E. 1952. Occurrence of voles, mice, and rats (Muridae) in Denmark, with a special note on a zone of intergradation between two subspecies of the house mouse (Mus musculus L.). Medd. Dansk. Naturhist. Forening, 114, 217-244.

YANG, S. Y., WHEELER, L. L., AND BOCK, I. R. 1972. IX. Isozyme variations and phylogenetic relationships in the Drosophila bipectinata species complex. Studies in Genetics, VII Univ. Texas Publ. 7213, 213-227.

zouros, E. 1973. Genic differentiation associated with the early stages of speciation in the mulleri subgroup of Drosophila. Evolution, 27, 601-621. 